\title{
A History of Pediatric Specialties
}

This article is the ninth in this series. It is a wonderful account of the history of vaccine development, complete with stories of serendipitous discoveries, the contributions of basic research and the threats posed by litigation and economic factors. This article describes the dramatic issues associated with the development of bacterial and virus vaccines and the role of molecular biology in future vaccine development. The prevention of infectious diseases in children by immunization, has been one of the greatest achievements of research in the history of medicine.

\section{Childhood Vaccine Development: An Overview}

\author{
JEFFREY P. BAKER AND SAMUEL L. KATZ \\ Departments of Pediatrics [J.P.B., S.L.K.] and History [J.P.B.], Center for the Study of Medical Ethics \\ and Humanities, Duke University Medical Center, Durham, North Carolina 27710, U.S.A.
}

\begin{abstract}
Vaccines against childhood diseases represent some of the most important applications of 20th-century pediatric research. This survey examines how the components of the current U.S. immunization schedule emerged in three phases during the course of the century. The first phase, after the development of bacterial culture techniques, witnessed numerous efforts in the early 1900 s to develop bacterial vaccines. It proved most fruitful with respect to diphtheria, tetanus, and pertussis. The rise of viral tissue culture techniques in the 1950s brought about a second phase of innovation resulting in vaccines against polio, measles, mumps, rubella, and varicella. A third wave of innovation, still very much alive, has drawn on a variety of new technologies and led to vaccines against hepatitis $\mathrm{B}$, Haemophilus influenzae type $\mathrm{b}$, pneumococcus, and still other organisms. Although basic science research has thus been a primary factor shaping the history of vaccine development, the collaboration between the
\end{abstract}

ABSTRACT

academic, private, and public sectors critical to its application has not always proceeded smoothly. The history of vaccine research and development has important implications for today, as a variety of factors threaten to fragment this network. (Pediatr Res 55: 347-356, 2004)
Abbreviations
BCG, bacille Calmette-Guérin
DTP, diphtheria-tetanus-pertussis
Hib, Haemophilus influenzae type b
IPV, inactivated poliomyelitis vaccine
MMR, measles-mumps-rubella
OPV, oral poliomyelitis vaccine
RSV, respiratory syncytial virus
SV40, simian virus 40

It is difficult to think of any specific medical intervention that has done so much to reduce childhood morbidity and mortality as has immunization. Yet the ease of administering vaccines in the clinic belies the complex history behind the

Received December 16, 2002; accepted July 25, 2003.

Correspondence: Jeffrey P. Baker, M.D., Ph.D., Department of Pediatrics, Box 3040, Duke University Medical Center, Durham, NC 27710, U.S.A.; e-mail: Baker009@mc.duke.edu

Supported in part by a grant from the Burroughs Wellcome Fund.

DOI: 10.1203/01.PDR.0000106317.36875.6A research and development of each of the products used commonly today. The current U.S. childhood immunization schedule can be viewed as a monument embodying this history, bearing witness to nearly a hundred years of basic and applied research. Some of its elements, such as the components of the familiar DTP combination, date back from before the Second World War. Polio, MMR, and varicella immunizations emerged from a second wave of viral vaccines grown in tissue culture beginning in the 1950s. The third phase of innovation, still very much under way, has been propelled by the applica- 
Table 1. History of licensing of childhood vaccines in the United States

$\begin{array}{ll}\text { Whole cell pertussis } & 1914 \\ \text { Diptheria toxoid } & 1926 \\ \text { Tetanus toxoid } & 1937 \\ \text { DT } & 1947 \\ \text { DTP } & 1948 \\ \text { DTaP } & 1996-1998 \\ \text { IPV } & 1955 \\ \text { OPV } & 1961-1963 \\ \text { Measles } & 1963 \\ \text { Mumps } & 1967 \\ \text { Rubella } & 1969 \\ \text { MMR } & 1971 \\ \text { MMR (RA 27/3) } & 1979 \\ \text { Hib polysaccharide } & 1985 \\ \text { Hib conjugated } & 1989-1990 \\ \text { HBV: plasma derived } & 1982 \\ \text { HBV: recombinant } & 1990 \\ \text { Mgc C } & 1974 \\ \text { Mgc A/C/Y/W 135 } & 1978 \\ \text { Mgc conjugates } & 2001 \text { (U.K., Canada) } \\ \text { Pnc 7 } & 1945 \\ \text { Pnc 14 } & 1977 \\ \text { Pnc 23 } & 1983 \\ \text { Pnc 7 conjugated } & 2000\end{array}$

Abbreviations: D, diphtheria; T, tetanus; $\mathrm{P}$, pertussis; aP, acellular pertussis; $\mathrm{Mgc}$, meningococcus; Pnc, pneumococcal; HBV, hepatitis B virus.

tion of both molecular biology and advanced chemistry techniques to develop such recent vaccines as recombinant hepatitis B and conjugated bacterial polysaccharides.

This essay will provide a brief overview of child vaccine development during the past century (Table 1). Given the breadth of this topic, two caveats are in order. The chief focus will be on vaccine research and development, not delivery. We will concentrate especially on vaccines recommended for universal use in children in the 20th century, as opposed to those reserved for high-risk populations.

\section{The Horse and the Cart: Science and Vaccines}

Vaccine development today is firmly grounded in basic science research. By contrast, one could argue that smallpox variolation and vaccination represented effective folk practices incorporated into mainstream medicine by astute observers. Variolation, the dermal application of small amounts of infective smallpox material to protect against future infection, had a long history in Asia and Africa before being introduced to western medicine. It was first used in the United States thanks to the vigorous advocacy of the Boston cleric Cotton Mather, who learned of the technique from African slaves and proceeded to apply it during Boston's 1721 smallpox epidemic. All except one of the city's physicians opposed him, and indeed Mather's experiment, although vindicated in hindsight, was not without considerable risk. Persisting doubt surrounding variolation eventually spurred the British physician Edward Jenner to test the belief of farmers and dairymaids that naturally acquired cowpox protected against smallpox. Jenner's subsequent decision in 1796 to vaccinate 8-y-old James Phipps is rightly remembered as a classic example of the experimental method in medicine. Yet it, too, derived less from scientific knowledge than from a well-disciplined empiricism. Even today the origins of vaccinia remain somewhat mysterious, given that molecular studies of the vaccine virus have proven identical with neither smallpox nor cowpox (1).

Louis Pasteur's successful extension of the vaccination principle to diseases besides smallpox represented a very different kind of innovation. Pasteur was a scientist, not a physician, whose work epitomized how the biomedical science of the day was fundamentally transforming concepts of diseaseespecially with respect to infection and immunity. He was also a master of public spectacle with a flair for self-promotion that sometimes obscured the patient laboratory work of his collaborators. It is now clear, for example, that Pasteur's discovery of the principle of attenuation in 1880 did not simply represent a serendipitous moment in which he decided to inject laboratory animals with a culture of chicken cholera inadvertently exposed to air during his summer holiday. It emerged instead out of a sustained program of laboratory research conducted by Pasteur's physician-associate Emile Roux. Pasteur moved remarkably quickly from this laboratory discovery to his widely publicized demonstrations of vaccines against sheep anthrax and human rabies in the 1880s. The inoculation of Joseph Meister in 1885 after a rabid dog's bite initially attracted considerable criticism from physicians (Roux himself did not participate), but was ultimately instrumental in making Pasteur a national hero rewarded by the creation of the institute that still bears his name (2). Interestingly, the event received little attention in the United States until several boys bitten by a rabid dog in Newark, NJ, were sent across the Atlantic to be treated by Pasteur himself. The Newark boys became media celebrities and even went on tour around the country, exemplifying on the popular level the promise of laboratory science (3).

Pasteur's work marked the beginning of the process by which laboratory science would transform vaccine development during the course of the subsequent century. It has done so in two broad ways. On the technical level, laboratory breakthroughs making it possible to cultivate and manipulate microorganisms in ever more precise ways have been critical forces driving innovation. One can therefore readily divide 20th-century vaccine development into three eras, respectively after the rise of bacterial culture techniques in the late 1800s, viral tissue culture in the 1950s, and molecular biology methods in the 1970s. On the theoretical level, the relationship is more complex. Vaccine development in the early 1900s typically proceeded in parallel with, if not ahead of, emerging concepts in immunology. Partly for that reason the widespread optimism characterizing many vaccine enthusiasts of the time proved to be premature. By the late 20th century, vaccine researchers could draw on a formidable body of basic science knowledge regarding microbiology and immunity, and therefore were able to produce more-specific and better-tolerated vaccines.

\section{Bacterial Vaccines: 1890-1950}

Beginning in the 1890s, investigators around the world scrambled to invent vaccines almost as quickly as new bacteria were discovered. Unfortunately, although culture techniques had made it possible to grow bacteria and subject them to 
various agents, it gradually became apparent that whole-cell bacteria were complex systems triggering equally complicated responses from the immune system. With the one possible exception of BCG, Pasteur's process of attenuation proved difficult to emulate among bacteria. Several other strategies were pursued instead. The discovery of the toxins associated with diphtheria and tetanus furnished ready-made targets leading to highly effective immunizations against both of these diseases. More problematic were the numerous attempts to create inactivated whole-cell vaccines during this period. Although many of these were directed against diseases relevant to military or tropical medicine, such as typhoid, plague, and cholera, pertussis vaccine emerged as well (4). These various strategies will be reviewed sequentially, culminating in the development of the DTP combination vaccine.

Live Bacterial Vaccines: BCG. Between 1908 and 1921, French bacteriologist Albert Calmette and veterinarian Camille Guérin developed BCG from a bovine mycobacterial strain passed more than 230 times in various media. After encouraging results from early clinical trials, French investigators played a key role in persuading the Health Committee of the League of Nations to adopt the vaccine in 1928. A major disaster soon followed, however, in Lübeck, Germany. Between 1929 and 1930 a contaminated BCG strain led to the deaths of at least 72 infants. A sensational trial of the three physicians involved took place in the autumn of 1931, attended by parents shouting from the galleries and a general atmosphere of social disintegration characteristic of the twilight of the Weimar republic. Germany rejected BCG. Yet the vaccine continued to have many defenders encouraged by favorable clinical trials and apparent success in other countries. After the Second World War, the First International Conference on BCG proclaimed the vaccine effective, leading to its use in greater than 4 billion people around the world in the course of campaigns by the World Health Organization and United Nations Children's Fund $(5,6)$.

Nonetheless, today it is fair to say that BCG is the most controversial, as well as the oldest, vaccine in current use. It never caught on in the United States. Before the 1940s, American public health leaders tended to view it as an unreliable technical "quick fix" that threatened to divert resources from tuberculin screening and personal hygiene education (7). The positive results from early clinical trials were subject to many of the criticisms that can be leveled at clinical investigation methods before the Second World War. When one takes into account all of the large clinical trials conducted from the 1930s through the 1970s, estimates of efficacy have ranged from 0 to $80 \%$. The reasons for such discrepancy have long been debated. The lack of a suitable marker of immunologic response has greatly complicated the design of field studies, as have variations in the composition of the vaccine itself. Although BCG likely does provide protection against tuberculous meningitis and disseminated disease in infancy, its efficacy against pulmonary disease remains uncertain $(5,8)$.

Toxin-Antitoxin: Diphtheria. During the 1870 s and 1880s, diphtheria still ranked as a major epidemic disease in childhood. In New York City, for example, case fatality rates ranged from 42 to $49 \%$. Physicians confronted with the awful specta- cle of a suffocating child in the death throes of the disease had little recourse beyond the surgical interventions of tracheostomy and, by the 1880 s, intubation. Yet the latter remained a difficult procedure, and even when successful could not counter the systemic effects of the disease toxin (9).

The first product to immunize against diphtheria was very different from the toxoid used today. German investigator Emil von Behring combined an extract of the deadly disease toxin with the antitoxin produced by its injection into healthy animals. In 1913 he announced that his first clinical trials with this "toxin-antitoxin" in children conferred immunity without significant adverse effects. In the same year Bela Schick of the University of Vienna published an account of a simple skin test that could confirm immunity to diphtheria (10). Armed with a plausible vaccine and a marker of immunity, conditions appeared right for a coordinated assault on the bacillus.

German aspirations were abruptly cut short by the onset of the First World War. In one of medical history's more interesting twists of fate, the opportunity to prove the efficacy of toxin-antitoxin now fell to the ambitious Director of Hygiene Services of the New York City Health Department, W.H. Park. A great admirer of von Behring's innovations, Park had himself been a pivotal figure in the city's earlier diphtheria antitoxin campaign. He recruited more than 100,000 children from the New York City public school system for a series of studies that eventually made him the world's leading proponent of diphtheria toxin-antitoxin. The New York City diphtheria campaigns of the 1920s, largely forgotten today, anticipated the polio campaigns of later years by taking advantage of newer media techniques such as flyers, posters, and film trailers to promote immunization. They also marked one of the earliest examples of mass vaccination through the school system $(11,12)$.

Toxoids: Diphtheria and Tetanus. Despite its great popularity in a number of U.S. cities, diphtheria toxin-antitoxin had significant adverse effects. Rare errors in balancing its two components could be devastating; one such incident in Dallas, TX, resulted in the deaths of five children. Another research strategy thus emerged after Paul Ehrlich's work suggesting that bacterial toxins might be modified chemically to induce immunity without toxicity. In Britain, where toxin-antitoxin was never licensed, Alexander Glenny and his colleagues developed such a product almost serendipitously during the early 1920s when they found that a batch of diphtheria toxin left in a large container cleaned with formalin had become less virulent yet still conferred immunity. Glenny thus by chance created a formalin-modified toxoid. His product, however, still incited significant adverse effects, and was only administered in combination with antitoxin (10).

The key figure in developing the first efficacious and welltolerated toxoid vaccines was the French investigator Léon Ramon of the Pasteur Institute. Ramon used both heat and formalin to generate a chemically modified toxin (which he termed anatoxin) with better properties than those of Glenny's toxoid in 1923. The French Academy of Medicine approved this vaccine for children in 1927. Ramon, it should be noted, also played a central role in developing tetanus toxoid between 1923 and 1926. In no small thanks to Ramon's advocacy efforts, France used diphtheria toxoid widely among children 
and tetanus toxoid among the military during the 1930s. The United States and most other industrialized countries followed suit during the course of the same decade, during which time diphtheria toxoid replaced toxin-antitoxin as the preferred form of the immunization for children. Tetanus toxoid also became a routine U.S. pediatric immunization after the licensure of the first combination product against diphtheria and tetanus in $1947\left(10^{\mathrm{p} 148}, 13\right)$.

Whole-Cell Vaccines: Pertussis. Efforts to immunize against whooping cough began almost as soon as Bordet discovered the causative bacteria in 1912. Yet the road to a successful vaccine proved arduous. The Danish physician Thorvald Madsen conducted particularly influential early studies, testing the vaccine during the periodic whooping cough epidemics sweeping the isolated Faroe Islands in the North Sea. His work inspired two investigators in the American Midwest during the 1930s, Louis Sauer and Pearl Kendrick. Unfortunately, there was no equivalent of the Schick test to demonstrate immunity to pertussis. The efficacy of whooping cough vaccine thus could only be tested in clinical trials. Kendrick took the important step of comparing immunized children to observed controls. Her work convinced the American Academy of Pediatrics to recommend pertussis vaccine during the early 1940s (14). In 1948 it was licensed in the United States in combination with diphtheria and tetanus toxoids to become the familiar DTP, a final critical innovation leading to its widespread use in American infants.

Interestingly, pertussis immunization did not become routine in Britain for an additional $10 \mathrm{y}$. There it played an important role in the history of the clinical trial. Thanks to the advocacy of Bradford Hill and others, the British Medical Research Council pioneered the use of randomized clinical trials in the immediate postwar years. Rather than follow the American lead, it embarked on a series of major randomized clinical trials involving more than 36,000 children that lasted until the late 1950s before ultimately confirming the vaccine's efficacy (15). After this final hurdle, DTP immunization became widespread in all industrialized countries.

\section{Viral Tissue Culture Vaccines: 1950-1970}

During the early 20th century investigators showed that unseen agents capable of passing through a bacteria-tight filter caused yellow fever, polio, and many other infectious diseases. These "filterable viruses," however, remained difficult to grow or manipulate. Despite Pasteur's early success with rabies vaccine developed in rabbit spinal cord preparations, few successful viral vaccines emerged before 1950. The chief exceptions were yellow fever and influenza vaccines grown in embryonated hens' eggs. Although inactivated influenza vaccines were used widely in the U.S. military during the Second World War, their poor performance during the 1947 epidemic demonstrated the significant impact of antigenic shift that has complicated their use ever since (16).

In the 1940s, however, the team of John Enders, Thomas Weller, and Frederick Robbins scored a great breakthrough that would transform vaccinology much as bacterial culture techniques had done in the previous century. This was the development of tissue culture as a medium by which to propagate and manipulate viruses. Ultimately this discovery would spawn an entire generation of new vaccines. The first to benefit, and indeed the one whose growth in tissue culture in 1949 would win for Enders and his team a Nobel prize, was that of the most-feared infectious disease in the United States at this time, poliomyelitis (17).

Polio. In 1937 the nation's most prominent polio victim, President Franklin D. Roosevelt, appointed his former law partner Basil O'Connor to direct the newly created National Foundation for Infantile Paralysis. Under his leadership this organization became a powerful advocate for vaccine development. Seeking funds from common citizens, not just the rich, radio spots around the nation solicited listeners to send dimes to Roosevelt on the occasion of his birthday. More than 2.5 million dimes were mailed in, overwhelming the White House mailroom and prompting later fund drives to be known as the "March of Dimes." (18) Yet the Foundation's efforts on behalf of a vaccine met with caution from researchers, beset by the memory of two failed trials of vaccine prepared in monkey spinal cord in the mid-1930s that led to the paralysis of several children and disgrace of the investigators (19).

The prospects for vaccine development for polio as well as other childhood viruses changed dramatically when Enders and his associates showed that the virus could be grown in tissue culture systems. Very promptly their techniques were exploited by Jonas Salk and Albert Sabin. Although mainstream scientific opinion favored Sabin's strategy of developing a live vaccine as most likely to induce enduring immunity, Salk attracted the attention of the national foundation through his promising early trials with IPV (20). The successful 1954 field trials involving nearly 2 million school children, announced dramatically to the popular press by director Thomas Francis, led to the immediate licensure of IPV and its rapid incorporation into the childhood immunization schedule (21). Despite the Cutter incident, in which early lots of the vaccine containing live virulent poliovirus resulted in the paralysis of 260 individuals, IPV continued to be regarded enthusiastically and was quickly embraced throughout Europe as well as the United States.

Running in parallel was the work of Albert Sabin, who now found it difficult to pursue clinical trials of his live attenuated OPV in the United States. There followed one of the most remarkable stories of international scientific cooperation during the Cold War. Sabin collaborated with Soviet investigators during the years of the "Kruschev thaw" to conduct trials in Russia and eastern European countries involving more than 10 million children. For a brief time afterward the Soviet Union became the world's leading producer of OPV, which consequently became regarded in the west as the "communist vaccine" until it was adopted by other nations. After a favorable report on the Soviet trials by Yale University's Dorothy Horstmann, the first monovalent OPV was licensed in 1960 (followed by a trivalent product in 1963) and fairly quickly became the vaccine of choice in the United States (22).

Although the conquest of polio has become of the great sagas of 20th-century medicine, both the Salk and Sabin vaccines took more than their share of lumps and bruises along the way. The Cutter incident, already mentioned, led to the 
resignation of President Eisenhower's secretary of Health, Education and Welfare in 1955. It is far from clear that production standards at Cutter laboratories were inferior to those anywhere else, as was charged at the time, and indeed the entire episode may well have reflected basic limitations with Salk's inactivation techniques (23). A second contamination incident occurred in 1960 when testing revealed that the monkey kidney tissues used to prepare the vaccine could be infected with SV40, a virus that was soon shown to be capable of causing tumors in hamsters and transforming human cells in tissue culture. The following year the U.S. government established standards to ensure that all new lots of polio vaccine were free of SV40. Fortunately, no conclusive evidence has emerged that this incident produced cancer in humans (although studies have continued to the present day) (24). Finally, live attenuated polio vaccine has been associated with a very small risk (estimated as 1 in 750,000 after the first dose) of inducing vaccine-associated paralytic poliomyelitis, which was not reported in the Soviet trials. As wild polio vanished from North America, and improved inactivated vaccines became available, the pendulum once again swung to the side of IPV, which today has become the recommended vaccine for routine childhood immunization (25).

Measles. The next tissue culture vaccine developed after polio was that for measles, a childhood illness with significant morbidity and mortality until then accepted as inevitable. Once again it was the Enders group that first propagated the Edmonston B strain of the virus that became the progenitor of subsequent vaccine strains (26). After successive passages in human kidney and amnion tissue cultures, and the amniotic sac of the embryonated hen's egg, Enders's associate Samuel Katz successfully developed an attenuated live vaccine using chick embryo cell culture. The vaccine was demonstrated to be efficacious and well tolerated in subsequent clinical investigations by Katz and others, leading to licensure of the first live measles vaccine in 1963. Although children receiving the vaccine often experienced fever and rashes, they were consistently noted to appear remarkably well. These relatively minor side effects nonetheless encouraged further attenuation of the vaccine into a still more benign product licensed in 1965 . Within several years the United States experienced a marked reduction of measles from several million cases per year to several thousand (27).

An interesting sidelight to measles vaccine was that, along with polio, it marked a victory for the advocates of live over inactivated vaccines. Two inactivated measles vaccines were developed by pharmaceutical companies in parallel with the live vaccine, and licensed in 1963. Both were eventually shown to induce partial immunity that, when challenged by wild measles, produced the atypical measles syndrome characterized by fever, headache, pneumonitis, and an unusual (sometimes petechial) rash. Nonetheless an estimated 1.8 million children were given this vaccine before its withdrawal in 1967 (28). The vaccines subsequently licensed for mumps, rubella, and eventually varicella were all live attenuated.

Efforts to control measles in the late 1960s were much more systematic than those involving polio $10 \mathrm{y}$ earlier. As the viral vaccine revolution continued to gain speed over the course of the decade, the need for some measure of coordination and central direction became increasingly evident. The American Academy of Pediatrics Committee on Infectious Diseases ("Red Book" Committee) had been making recommendations on vaccines directed at private practitioners since 1938. In 1964 the Surgeon General established the Advisory Committee on Immunization Practices to play an analogous role directed especially at the public health sector. In practice the two groups (joined more recently by the American College of Family Physicians) have rarely diverged significantly in recommending and revising childhood immunization schedules (29).

Rubella. Rubella vaccine was developed not so much because of the severity of the disease itself, but its effects on the fetus. Cases of congenital rubella peaked every $6-9$ y in the United States. During the 1964-1965 epidemic alone, more than 20,000 infants were born with manifestations of the congenital rubella syndrome; 1,790 of these children were left mentally retarded and 8,000 deaf (30). Public anxiety generated great pressure to develop a vaccine before the next pandemic was expected in the 1970s. By 1969, investigators at Merck laboratories (led by Maurice Hilleman, whose team had also been instrumental in the later attenuation of measles vaccine) and the Division of Biologics Standards had both developed candidate vaccine strains. The Division of Biologics Standards strain won out, and the congenital rubella epidemic expected to recur in the early 1970s in the United States never took place $(31)^{\mathrm{p} 103-114}$. Rubella did continue to appear among underimmunized populations in several nations in which the vaccine had not yet been adopted (32).

Rubella also marked the first example of a live attenuated vaccine grown in human diploid cells rather than animal tissue culture. The lessons of the SV40 episode were not lost on researchers in their efforts to develop safer vaccines. Stanley Plotkin and others developed a rubella vaccine grown in human fibroblasts as an alternative in 1971 that was rapidly licensed in Europe. These cells, derived from human fetal fibroblasts, were initially controversial in the United States because of fears that they might contain latent human cancer viruses and therefore predispose to malignancy. Finally licensed in 1979, the RA27/3 strain has remained in use in the United States to the present day, providing a safe product that has continued to prove highly effective in preventing congenital rubella (33).

MMR. In 1971, Merck laboratories again scored a major breakthrough with the licensure of its trivalent MMR vaccine. Hilleman had already developed a mumps vaccine in 1969 from a strain cultivated from his own daughter, Jeryl Lynn, tested with the help of clinical investigators in Philadelphia (34). But the vaccine remained something of an orphan during the late 1960s in comparison to measles and rubella. Measles eradication efforts suffered at the same time as national attention and federal funding shifted abruptly to rubella in 1969, and indeed disease rates rose modestly during the early 1970s. The MMR combination, coupled with a renewed political commitment to promote vaccination under the Carter administration, resulted in remarkably low levels of all three infections until 1989. That year witnessed new epidemics of measles principally among adolescents and young preschool unvaccinated children. This led to the institution of a second MMR dose to 
address those children who had failed to convert after their initial dose (estimated as 5\% in research trials but as high as $10-15 \%$ in actual practice). Efforts to boost immunization rates in the second year of life followed (35). As a result, since 1993 there has been no indigenous measles in the United States. Of the approximately 100 cases of measles reported annually in the United States during the years 1997-2002, nearly all that have been available for molecular epidemiologic study have been proven to be importations (36).

\section{A Time of Transition: 1970-1985}

The 1970s marked a period of uncertainty for childhood immunizations. With the exception of varicella immunization in Japan, no new live attenuated vaccines were introduced for routine use. Researchers during these years renewed their interest in bacterial polysaccharide vaccines (most notably meningococcal and multivalent pneumococcal vaccines) and inactivated vaccine against hepatitis B virus. Still, it would be some time before this important work would be incorporated into the routine childhood immunization schedule. The American Academy of Pediatrics failed to recommend a single new immunization for universal use in childhood between the licensure of MMR in 1971 and the first capsular vaccine for Hib in 1985 . To some extent this relative loss of momentum simply reflected the time and expenses required in the laboratory and clinical trials to develop a new generation of vaccines. Yet ominous economic and legal developments became evident during these years as well.

During the 1970s, pharmaceutical companies, critical to vaccine development during the previous decade, increasingly questioned the return on their investment. Low profit margins were in part to blame. As the federal government became increasingly involved in providing vaccines after the Vaccination Assistance Act of 1962, manufacturers contended with low negotiated prices in the public health sector. DTP, for example, at one point was sold for just 10 cents a dose. While their European counterparts were compensated by substantial governmental support and protection, U.S. pharmaceutical companies were left to rely on the private sector for profits. Vaccine development from this perspective offered a less promising investment for many firms than other breakthrough drugs emerging from the research pipeline $(31)^{\mathrm{p} 145-149}$.

Compounding this problem was a second, the rise of vaccine victim litigation after the 1974 ruling of Reyes $v$ Wyeth. In this case, the parents of a southern Texas child allegedly paralyzed with OPV successfully sued the vaccine's manufacturer for allowing the product to be given in public health clinics without ensuring consent. The court ruled against the manufacturer even though laboratory studies had indicated the child's illness to have resulted from a strain of wild polio prevalent at the time in neighboring Mexico. The case set the stage for the swine flu debacle of 1976, which triggered a major round of lawsuits after epidemiologic study suggested an association (since contested but never disproved) between influenza vaccine and Guillain-Barré syndrome $(37,38)$. Legal and economic pressure thus rose insidiously throughout the seventies (39). By 1982 there remained only one manufacturer each for OPV and MMR, and three for the venerable DTP (40).

These worrisome trends escalated rapidly after the 1982 airing of DPT: Vaccine Roulette. This television documentary, vividly depicting the lives of profoundly disabled children allegedly injured by pertussis vaccine, sent the entire national vaccine network into turmoil. Thanks in part to vigorous counter-publicity by the American Academy of Pediatrics, the media coverage did not cause immunization rates to plummet (and whooping cough cases to rise) as had been the case in Britain, Japan, and other countries during the previous decade. But the controversy did ignite a crisis in the courts, as a record number of lawsuits led to the withdrawal of two of the remaining three DTP manufacturers by July 1985 (41). The crisis was finally averted through passage of the National Childhood Vaccine Injury Act in the following year. This legislation set up a program to compensate victims of alleged vaccine adverse reactions without having to resort to the tort system. Despite ongoing controversy surrounding what kinds of conditions deserve compensation, the act has proved an effective if pragmatic deterrent to lawsuits. It has also provided a reliable mechanism for scientifically validated review of possible injuries brought to the program's attention $(39,42)$.

\section{The Third Vaccine Revolution: 1985-Present}

Even as the older pertussis vaccine and OPV were coming under fire (the latter for rare cases of vaccine-associated paralysis), technological developments placed investigators on the threshold of the most fruitful wave of innovation since the 1950s and 1960s. The Institute of Medicine helped galvanize interest through the release of its 1985 report announcing a well-planned set of new vaccine development priorities among which were hepatitis B, Haemophilus influenza type b, RSV, and varicella (43). Many of its targeted immunizations emerged in the years to follow, although not necessarily in the time frame predicted.

Hepatitis $\boldsymbol{B}$. An important factor behind the renewed optimism characterizing vaccine development in the 1980s was the potential of using recombinant DNA technology to produce specific subunit vaccines. One such product was developed remarkably soon after the Institute of Medicine report. Hepatitis B virus had long presented especially formidable challenges for vaccine development because it could not be grown in tissue culture and infected no animals other than higher primates. Pediatric investigator Saul Krugman, however, successfully prepared a heat-inactivated vaccine from the plasma of chronically infected patients that became the basis for a manufactured vaccine in the early 1980s. Unfortunately this product became widely available in 1982 just as the incipient AIDS epidemic cast suspicion on all plasma-derived products. This unexpected reversal set the stage for the first venture to develop a vaccine via the new technology of recombinant DNA. After attempts to insert the surface antigen gene into Escherichia coli failed to produce the correct threedimensional configuration, investigators accomplished their purpose through the substitution of eukaryotic yeast as host. Developed in collaboration with academic researchers and 
biotechnology firms, Merck's Recombivax HB was licensed in 1986 and rapidly disseminated among at-risk adults. In 1992 the vaccine was recommended for all children $\left(31^{\mathrm{p} 183-205}, 44\right)$.

Acellular Pertussis. The road to the licensure of an effective acellular pertussis vaccine, on the other hand, proved much longer than expected. Japanese investigators introduced an acellular product in 1981 in the course of their own pertussis vaccine controversy. Yet because it was initially provided for children at age $2 \mathrm{y}$, its immunogenicity among infants (who experienced the worst complications of whooping cough) remained uncertain (45). Clinical trials to answer this question had to be conducted abroad among countries not routinely using the vaccine. The first large trials, conducted in Sweden in the mid-1980s, demonstrated efficacies of only $54 \%$ and $69 \%$, respectively, for the monovalent and bivalent products tested. Introduction of acellular pertussis vaccine was consequently delayed for more than $10 \mathrm{y}$ until further studies of vaccines (ranging from monovalent to pentavalent) tested in Italy, Germany, and Sweden finally produced convincing evidence supporting their use. Licensure for infants in the United States finally came in 1996 (46). Ironically, by this time the Institute of Medicine had concluded in its detailed 1991 review of pertussis vaccine side effects that the alleged connection between whole-cell vaccine and permanent neurologic disability remained unproven (47).

Varicella. Live varicella vaccine represented another case in which a vaccine developed in Japan was not licensed in the United States for another $15 \mathrm{y}$. In many ways this vaccine belongs to the polio-MMR era of live tissue culture vaccines, as Japanese investigators attenuated the Oka strain of this virus during the early 1970s. Yet it differed in being the first live viral vaccine to be developed for immunocompromised as well as normal children. In the United States Anne Gershon and her coworkers first tested it among leukemic children in remission, among whom chicken pox incurred significant illness and mortality, through a large collaborative study begun in 1979 (48). Once demonstrated to be safe and effective among these youngsters, the great question was whether it should be applied to healthy children in whom the disease was relatively mild. Like other herpes viruses, varicella becomes latent after primary infection, and initially there was no way to know the effects of vaccination on the incidence of zoster in later life. Close follow-up for many years of children enrolled in the first collaborative trials among leukemic youngsters has revealed that the vaccine actually decreases the chance of zoster, a trend that so far appears to apply to healthy children as well. The vaccine was finally licensed in 1995 and incorporated into the schedule alongside the 12-mo MMR (49). It may also be offered on an individual basis to leukemic children who have been in remission for greater than a year. Current studies are exploring whether an adult dose of varicella vaccine might further diminish the incidence of zoster in the geriatric population.

Haemophilus influenzae type b. In terms of impact on child health, the development of conjugate vaccines against encapsulated bacteria has represented the greatest vaccine breakthrough of the late 20th century. Yet it is worth noting that these were not products of molecular biology technology in the usual sense of the word, but in many ways drew on insights and techniques developed earlier in the century. By the late 20th century, Hib, pneumococcus, and meningococcus continued to rank among the most lethal pathogens of early childhood. This led to renewed interest in the older capsular vaccines as well as finding a means to induce protective immunity in younger infants. Development of an Hib vaccine began during the 1960s, spearheaded by two teams of investigators under the leadership of David Smith and Porter Anderson in Boston (and later Rochester, NY) and John Robbins and Rachel Schneerson at the National Institutes of Health. The collaboration between these laboratories, and indeed the general spirit of calm accompanying the development of the Hib vaccine, contrasted markedly with the rivalries of the polio period. Smith and Anderson tested the first purified Hib capsular polysaccharide vaccine in Salem, MA, demonstrating it to be $87 \%$ effective in inducing antibody response among children older than $2 \mathrm{y}$ of age but only $22 \%$ among infants (50). The publication of the 1973 Salem trial was followed by the vaccine's use as a control in a larger Finnish study of meningococcal A vaccine that further confirmed its poor efficacy among infants (51). Although the latter trial eventually led to the licensure of the first Hib vaccine for use at age $2 \mathrm{y}$ in 1985 , the search for a means to induce earlier immunogenicity continued unabated.

The answer came from the rediscovery of a technique developed before 1940. Drawing on Karl Landsteiner's articulation of hapten-carrier theory, Oswald Avery and W.F. Goebel had succeeded in inducing antibodies in the mouse model by binding the nonimmunogenic pneumococcal capsular polysaccharide to a protein carrier. Both groups of investigators drew on this earlier research to develop the first Hib conjugate vaccines. Introduced for 18-mo-olds in 1987 and all infants in 1990, the widespread use of these and other conjugated Hib products was associated with a $99 \%$ decline of incidence of invasive Hib disease between 1987 and 1996, which has since been sustained $(52,53)$.

Pneumococcus. The road to the development of a pneumococcal conjugate vaccine proved to be still more arduous. Two pneumococcal polysaccharide vaccines had been introduced after the Second World War only to be withdrawn after the antibiotic revolution. The work of investigator Robert Austrian showing that the case fatality rate of bacteremic pneumococcal pneumonia remained substantial even with antibiotic therapy rekindled interest during the 1970s, however. Merck produced a 14-valent product licensed in 1977 and a 23-valent counterpart in 1983. These polysaccharide vaccines had little efficacy in infants, and found their chief application among medically vulnerable children and adults (54). Immediately after the licensure of Hib conjugate vaccine in 1987, the National Institute for Allergy and Infectious Diseases sought to interest industry in developing a seven-valent conjugate immunization against pneumococcus. Only Praxis Biologics, a new venture led by ex-pediatric professor (and associate of Porter Anderson) David Smith of the University of Rochester, submitted a contract. Years were required developing the vaccine, incorporating three, then five, then finally seven conjugated polysaccharide-proteins. Phase I trials proceeded even as Praxis was absorbed by Wyeth-Lederle. Prevnar was finally licensed in 
February 2000, more than 20 y after the 14-valent capsular vaccine. Although its universal application thus far has been somewhat impeded by cost and supply shortages, this immunization has already demonstrated its effectiveness in preventing the complications of invasive pneumococcal disease in the face of growing antibiotic resistance $(55,56)$.

Meningococcus. Still another effective conjugate vaccine has been developed against meningococcal disease. Here the United Kingdom has led the way. The high complication rate and predilection for school outbreaks of meningococcus have long marked it as an illness especially loathed by parents and doctors, yet interest in a vaccine has been impeded by the failure thus far to develop an effective product against the B serotype most characteristic of industrialized countries. In Britain, as well as in Canada and a number of other European countries, serotype $\mathrm{C}$ for uncertain reasons became increasingly significant during the 1990s. In November 1999 the U.K. Department of Health launched a highly successful immunization campaign using a newly developed conjugate vaccine targeting meningococcal serotype $\mathrm{C}$. The campaign offered the vaccine both to infants as part of their regular schedule as well as to school-age children on a catch-up basis. Within $18 \mathrm{mo}$, vaccine coverage rates of approximately $85 \%$ were achieved and the incidence of serogroup $\mathrm{C}$ disease fell by more than $80 \%$ (57). The vaccine by now has been licensed in Canada and used widely in Spain and other European countries as well. Meanwhile in the United States, where serotype C is less common and many babies are already receiving four immunizations at some of their well-child visits, its use will likely have to await development of a group B vaccine and newer combination vaccines. At this point the American Academy of Pediatrics recommends considering the older nonconjugated meningococcal vaccine (covering serogroups A,C, W135, and Y) for precollege students.

\section{CONCLUSIONS}

Three observations emerge from this review of the history of vaccine development. The first may be stated simply: it is basic science, not mere political will, that makes possible great leaps in vaccine innovation. Whereas investigators in the early $1900 \mathrm{~s}$ confidently predicted the imminent control of all kinds of diseases through killed whole-cell immunizations, in reality vaccines have emerged in a series of distinct phases triggered by specific breakthroughs in the laboratory. Most of the empirically designed whole-cell vaccines of the early 1900s have long since been discarded from use. The national foundation's support for polio vaccine research only bore fruit after the discovery of tissue culture techniques and the successful typing of polio virus. Today, political pressure to develop an effective vaccine against HIV raises similar questions of how realistic such hopes are against the novel challenges posed by this highly mutable retrovirus. Efforts to develop an RSV vaccine will likewise require understanding why an inactivated product tested during the 1960s resulted in higher morbidity and mortality rates among clinical trial subjects.

A second striking theme apparent from the history of vaccine development is the ever-greater emphasis on ascertaining efficacy and safety through rigorous clinical trials and postlicensure monitoring. During the heroic years of early 20thcentury vaccinology, immunizations were indeed often introduced with remarkable speed to a public eager for the latest miracle afforded by medical science. Many of the whole-cell vaccines used during these years were later rejected, and others induced considerable toxicity or even deaths (as with diphtheria toxin-antitoxin). The Cutter incident complicating and temporarily disrupting the introduction of the Salk vaccine has long been a symbol, rightly or wrongly, of the dangers of over-accelerating the introduction of a vaccine. One can, to be sure, argue that more lives would have been lost had no vaccine for polio been available that year. The point deserving emphasis is simply that there is always a tradeoff between the efficacy and safety standards applied to a vaccine and the time required for its development and licensure. During the past $20 \mathrm{y}$, childhood vaccines have been introduced only after prolonged periods of clinical study; even so, one (rotavirus vaccine) was withdrawn within a year after its release when postlicensure monitoring revealed a rare association with intussusception (58). The incident underscored the effectiveness of today's vaccine adverse effect surveillance system, but represented a financial disaster for the manufacturer and a major setback for children in developing countries who stood to gain the most from a vaccine. A low tolerance for risk translates into a longer time for vaccine introduction. Conversely, political pressure to introduce a vaccine quickly (as has been mounting with concerns of bioterrorism from anthrax and smallpox) invokes greater risk.

A final observation is that vaccine development has become an increasingly complex and large-scale enterprise, involving the academic, corporate, and government sectors. Although vaccine discoveries were never as straightforward as conveyed by the mythology of Pasteur's decision to inoculate Joseph Meister, without doubt they have come to involve much larger networks of individuals and organizations. Here again, tradeoffs are inevitable. Public intolerance for even low vaccine risks, as well as government pressure to keep prices low, makes vaccine development less attractive to corporations. Recent vaccine shortages and the withdrawal of vaccines against rotavirus and Lyme disease highlight a worrisome trend, the continued concentration of vaccine development among an increasingly small number of manufacturers. At present only two major U.S.-based pharmaceutical firms (Merck and Wyeth-Lederle) and two multinational firms (Aventis Pasteur and GlaxoSmithKline) provide the entire supply of routine childhood immunizations (not counting influenza) in this country. This figure compares with seven in 1985 and twice that number in $1966(59,60)$.

Contemporary discussion of this problem rarely acknowledges its deep historical roots. Vaccine development has relied on an informal network of academic researchers, biotechnology firms, manufacturers, and government agencies that evolved in the wake of the success of the Salk vaccine in the 1950s. Manufacturers are critical to its success, yet vaccines have not been nearly as profitable in recent years as other new drugs given for common chronic conditions of adulthood. A United Nations Children's Fund study in the early 1990s, for 
example, showed that the best-selling drug Zantac brought in more income ( $\$ 3.5$ billion) than the entire global vaccine market during the same year (61).

Public health and pediatric leaders will need to be increasingly aware of the close interplay among policies directed at vaccine research, development, safety, and delivery. Assuming this is the case, as the 21 st century opens the prospects for new vaccine development have in many ways never been brighter. After a lull in the mid-1990s, federal levels of support for vaccine development have increased considerably. An amazing array of new techniques for vaccine design and delivery are being explored. Work is proceeding, for example, to develop more effective mucosal vaccines to be delivered by the intranasal or oral route. Besides being easier to administer, such vaccines would have the advantage of stimulating immunity in the very tissues targeted by their associated organisms, as well as inducing systemic humoral immunity. As of June 2003, the U.S. Food and Drug Administration has just licensed a live attenuated intranasal influenza vaccine. Increased knowledge of the genetic components responsible for boosting cellular immunity has heightened interest in DNA vaccines. Plasmids are being studied as tools by which to introduce the DNA coding to express the target protein in the cytoplasm of an antigen-presenting cell. The near future may well witness the introduction of a live vaccine against RSV as well as effective immunizations against human papilloma and herpes simplex viruses. Conjugated meningococcal vaccine, as mentioned, is already used in Britain and Canada and could soon be available in the United States. The list of other possible vaccines is too long to enumerate, and includes candidates ranging from $\mathrm{Hel}$ icobacter pylori and group B streptococci to the more formidable challenges of HIV, tuberculosis, and malaria (62). Given the record of the past century, it is difficult not to be optimistic about what the 21 st may hold for vaccinology.

Acknowledgment. The authors thank the American Pediatric Society and its council for stimulating and supporting the activities of the Workgroup on History, chaired by Laurence Finberg, M.D., and E. Richard Stiehm, M.D., which resulted in this manuscript.

\section{REFERENCES}

1. Radetsky M 1999 Smallpox: a history of its rise and fall. Pediatr Infect Dis 18:85-93

2. Geison GL 1995 The Private Science of Louis Pasteur. Princeton University Press, Princeton, NJ, pp 177-258

3. Hansen B 1998 America's first medical breakthrough: how popular excitement about a French rabies cure in 1885 raised new expectations for medical progress. Am Hist Rev 103:373-418

4. Foster WD 1970 A History of Medical Bacteriology and Immunology. William Heinemann Medical Books, London, UK, pp 127-164

5. Smith KC, Starke JR 1999 Bacille Calmette-Guérin. In: Plotkin SA, Orenstein W (eds) Vaccines, 3rd Ed. WB Saunders, Philadelphia, pp 111-139

6. Smith FB 1988 The Retreat of Tuberculosis, 1850-1950. Croom Helm, London, UK, pp 194-203

7. Feldberg GD 1995 Disease and Class: Tuberculosis and the Shaping of Modern North American Society. Rutgers University Press, New Brunswick, NJ, pp 1-214

8. Colditz GA, Brewer TF, Berkey CS, Wilson ME, Burdick E, Fineberg HV, Mostelle F 1994 Efficacy of BCG vaccine in the prevention of tuberculosis: meta-analysis of the published literature. JAMA 271:698-702

9. Metaxas Quiroga VA 1990 Diphtheria and medical therapy in late 19th century New York City. NY State J Med 90:256-262

10. Parish HJ 1965 A History of Immunization. E.\& S. Livingstone, Edinburgh, pp 141-154

11. Park WH 1923 The control of diphtheria. Am J Public Health 13:23-32
12. Hammonds EM 1999 Childhood's Deadly Scourge: The Campaign to Contro Diphtheria in New York City, 1880-1930. Johns Hopkins University Press, Baltimore, pp 1-299

13. Lévy FM 1975 The fiftieth anniversary of diphtheria and tetanus immunization. Prev Med 4:226-237

14. Elderling G 1971 Symposium on pertussis immunization, in honor of Dr. Pearl L. Kendrick in her eightieth year: historical notes on pertussis immunization. Health Lab Sci 8:200-205

15. Medical Research Council 1959 Vaccination against whooping-cough: the final report to the whooping cough committee of the Medical Research Council. BMJ 1:994-1000

16. Kilbourne ED 1996 A race with evolution - a history of influenza vaccines. In: Plotkin SA, Fantini B (eds) Vaccines, Vaccination, Vaccinology: Jenner, Pasteur and Their Successors. Elsevier, Amsterdam, pp 183-188

17. Enders JF, Weller TH, Robbins FC 1949 Cultivation of the Lansing strain of poliomyelitis virus in cultures of various human embryonic tissues. Science 109:85-87

18. Smith JS 1990 Patenting the Sun: Polio and the Salk Vaccine. William Morrow and Co, New York, pp 1-378

19. Berk LB 1989 Polio vaccine trials of 1935. Trans Stud Coll Physicians Phila 11:321-337

20. Bendiner E 1983 Salk: adulation, animosity, and achievement. Hosp Pract 18:194-218

21. Lambert SM, Markel H 2000 Making History: Thomas Francis, Jr MD, and the 1954 Salk Poliomyelitis Vaccine Field Trial. Arch Pediatr Adolesc Med 154:512-517

22. Benison S 1982 International medical cooperation: Dr. Albert Sabin, live poliovirus vaccine, and the Soviets. Bull Hist Med 56:460-483

23. Nathanson N, Langmuir AD 1963 The Cutter incident-poliomyelitis following formaldehyde-inactivated poliovirus vaccination in the United States during the spring of 1955. Am J Hyg 78:16-81

24. Immunization Safety Review Committee, Institute of Medicine 2002 Immunization Safety Review: SV40 Contamination of Polio Vaccine and Cancer. National Academies Press, Washington, DC, pp 1-72

25. Robbins FC 1999 The history of polio vaccine development. In: Plotkin SA, Orenstein W (eds) Vaccines, 3rd Ed. WB Saunders, Philadelphia, pp 13-27

26. Enders JF, Katz SL, Milovanovic MB, Holloway A 1960 Studies on an attenuated measles virus vaccine. I. Development and preparation of the vaccine. N Engl J Med 263:153-159

27. Katz SL 1996 The history of measles vaccine and attempts to control measles. In: Koprowski H, Oldstone MBA (eds) Microbe Hunters-Then and Now. Medi-Ed Press, Bloomington, IL, pp 69-76

28. Fulginiti VA, Eller JJ, Downie AW, Kempe CH 1967 Altered reactivity to measles virus: atypical measles in children previously immunized with inactivated measles virus vaccines. JAMA 202:1075-1080

29. Vivier PM 1996 National Policies for Childhood Immunization in the United States: An Historical Perspective. Dissertation, Johns Hopkins University, UMI Dissertation Services, Ann Arbor, MI, pp 77-78

30. Plotkin SA 1999 Rubella vaccine. In: Plotkin SA, Orenstein W (eds) Vaccines, 3rd Ed. WB Saunders, Philadelphia, pp 409-440

31. Galambos L, Sewell JE 1995 Networks of Innovation: Vaccine Development at Merck, Sharp \& Dohme, and Mulford, 1895-1995. Cambridge University Press, Cambridge, UK, pp 1-255

32. Owens CS, Espino RT 1989 Rubella in Panama: still a problem. Pediatr Infect Dis $8: 110-115$

33. Plotkin SA 1996 History of rubella vaccines and the recent history of cell culture. In: Plotkin SA, Fantini B (eds) Vaccines, Vaccination, Vaccinology: Jenner, Pasteur and Their Successors. Elsevier, Amsterdam, pp 271-282

34. Buynak EB, Hilleman MR 1966 Live attenuated mumps virus vaccine: 1 . Vaccine development. Proc Soc Exp Biol Med 123:768-775

35. National Vaccine Advisory Committee 1991 The measles epidemic: the problems, barriers, and recommendations. JAMA 266:1547-1552

36. Rota PA, Liffick SL, Rota JS, Katz RS, Redd S, Papania M, Bellini WJ 2002 Molecular epidemiology of measles viruses in the United States: 1997-2001. Emerg Infect Dis 8:902-908

37. Silverstein AM 1981 Pure Politics and Impure Science: The Swine Flu Affair. Johns Hopkins University Press, Baltimore, pp 1-176

38. Kurland LT, Wiederholt WC, Kirkpatrick JW, Potter HG, Armstrong P 1985 Swine influenza vaccine and Guillain-Barré syndrome: epidemic or artifact? Arch Neurol 42:1089-1090

39. Kitch EW, Evans G, Gopin R 1999 U.S. law. In: Plotkin SA, Orenstein W (eds) Vaccines, 3rd Ed. WB Saunders, Philadelphia, pp 1165-1185

40. Hearing before the Subcommittee on Investigations and General Oversight of the Committee on Labor and Human Resources, U.S. Senate, 97th Congress, 2nd session, July 22, 1982, pp 1-5

41. Hinman AR 1986 DTP vaccine litigation. Am J Dis Child 140:528-530

42. Smith MH 1988 National Childhood Vaccine Injury Compensation Act. Pediatrics $82 \cdot 264-269$

43. Institute of Medicine 1985 New Vaccine Development: Establishing Priorities. National Academy Press, Washington, DC, pp 1-458

44. Valenzuela P, Medina A, Rutter WJ, Ammerer G, Hall BD 1982 Synthesis and assembly of hepatitis B virus surface antigen particles in yeast. Nature 298:347-350

45. Kumura M. Kuno-Sakai H 1991 Pertussis vaccines in Japan - a clue towards understanding of Japanese attitude to vaccines. J Trop Pediatr 37:45-47

46. Edwards KM, Decker MD 1996 Acellular pertussis vaccines for infants. N Engl J Med 334:391-392

47. Institute of Medicine 1991 Adverse Effects of Pertussis and Rubella Vaccines. National Academy Press, Washington, DC, pp 86-118 
48. Gershon A, Steinberg S, Gelb L, NIAID Collaborative Varicella Vaccine Study Group 1984 Live attenuated varicella vaccine: efficacy for children with leukemia in remission. JAMA 252:355-362

49. Gershon A, LaRussa P, Steinberg S 1996 Live attenuated varicella vaccine. In: Koprowski H, Oldstone MBA (eds) Microbe Hunters-Then and Now. Medi-Ed Press, Bloomington, IL, pp 173-184

50. Smith DH, Peter G, Ingram DL, Harding AL, Anderson P 1973 Responses of children immunized with capsular polysaccharide Haemophilus influenzae type b. Pediatrics 52:637-644

51. Peter G 1998 Commentary. Pediatrics 102:252-253

52. Robbins JB, Schneerson R 1990 Polysaccharide-protein conjugates: a new generation of vaccines. J Infect Dis 161:821-832

53. [ No authors listed] 2002 Progress toward elimination of Haemophilus influenzae type b invasive disease among infants and children-United States, 1998-2000. MMWR Morb Mortal Wkly Rep 51:234-237

54. Austrian R 1999 A brief history of pneumococcal vaccines. Drugs Aging 15(sup$\mathrm{pl)}: \mathrm{S} 1-\mathrm{S} 9$

55. Advisory Committee on Immunization Practices, Centers for Disease Control 2000 Preventing pneumococcal disease among infants. MMWR Morb Mortal Wkly Rep 49:1-38
56. Jordan W 2002 Jordan perspective: pneumococcal vaccine. In: National Institute of Allergy and Infectious Diseases, The Jordan Report 20th Anniversary: Accelerated Development of Vaccines 2002. Government Printing Office, Washington, DC, pp 207-208

57. Miller E, Salisbury D, Ramsay M 2002 Planning, registration, and implementation of an immunization campaign against meningococcal serogroup $\mathrm{C}$ disease in the UK: a success story. Vaccine 20(suppl):S58-S67

58. Rennels MB 2000 The rotavirus vaccine story: a clinical investigator's view. Pediatrics 106:123-125

59. Mowery DC, Michell V 1995 Improving the reliability of the U.S. vaccine supply: an evaluation of alternatives. J Health Polit Policy Law 20:973-999

60. National Vaccine Advisory Committee 1997 U.S. vaccine research: a delicate fabric of public and private collaboration. Pediatrics 100:1015-1020

61. [ No author listed] 1994 Bumps on the vaccine road. Science 265:1371-1379

62. Liu MA, Ulmer JB, O'Hagan D 2002 Vaccine technologies. In: National Institute of Allergy and Infectious Diseases, The Jordan Report 20th Anniversary: Accelerated Development of Vaccines 2002. Government Printing Office, Washington, DC, pp $39-43$ 